\title{
A Multidisciplinary Approach for Nonresponders Following Bariatric Surgery: What Is the Value?
}

Citation for published version (APA):

Romeijn, M. M., Uittenbogaart, M., van Dielen, F. M. H., Luijten, A. A. P. M., Janssen, L., \& Leclercq, W. K. G. (2022). A Multidisciplinary Approach for Nonresponders Following Bariatric Surgery: What Is the Value? Bariatric Surgical Practice and Patient Care, 17(1), 9-16. https://doi.org/10.1089/bari.2021.0025

Document status and date:

Published: 01/03/2022

DOI:

10.1089/bari.2021.0025

Document Version:

Publisher's PDF, also known as Version of record

Document license:

Taverne

Please check the document version of this publication:

- A submitted manuscript is the version of the article upon submission and before peer-review. There can be important differences between the submitted version and the official published version of record.

People interested in the research are advised to contact the author for the final version of the publication, or visit the DOI to the publisher's website.

- The final author version and the galley proof are versions of the publication after peer review.

- The final published version features the final layout of the paper including the volume, issue and page numbers.

Link to publication

\footnotetext{
General rights rights.

- You may freely distribute the URL identifying the publication in the public portal. please follow below link for the End User Agreement:

www.umlib.nl/taverne-license

Take down policy

If you believe that this document breaches copyright please contact us at:

repository@maastrichtuniversity.nl

providing details and we will investigate your claim.
}

Copyright and moral rights for the publications made accessible in the public portal are retained by the authors and/or other copyright owners and it is a condition of accessing publications that users recognise and abide by the legal requirements associated with these

- Users may download and print one copy of any publication from the public portal for the purpose of private study or research.

- You may not further distribute the material or use it for any profit-making activity or commercial gain

If the publication is distributed under the terms of Article $25 \mathrm{fa}$ of the Dutch Copyright Act, indicated by the "Taverne" license above, 


\title{
A Multidisciplinary Approach for Nonresponders Following Bariatric Surgery: What Is the Value?
}

\author{
Marleen M. Romeijn, MD, ${ }^{1,2,{ }^{\star}}$ Martine Uittenbogaart, MD, ${ }^{1}$ François M.H. van Dielen, MD, PhD, ${ }^{1}$ \\ Arijan A.P.M. Luijten, MD, Loes Janssen, PhD, ${ }^{1}$ and Wouter K.G. Leclercq, MD ${ }^{1}$
}

Background: Approximately 25\% of patients after bariatric surgery either do not lose enough weight or regain a considerable amount of weight, both are referred to as nonresponse. This study aimed to describe the added value of a multidisciplinary approach on treatment strategies in patients with nonresponse.

Materials and Methods: The primary outcome of this retrospective cohort study was the initiated treatment by the multidisciplinary team (MDT). Outcomes were described separately for patients with primary (i.e., $<50 \%$ excess weight loss [EWL]) and secondary nonresponse (i.e., $\geq 50 \%$ EWL followed by $>5 \%$ regain).

Results: Of the 83 included patients, 10 patients underwent revisional surgery. A total of 73 patients received a conservative treatment as they either had not been able to change their lifestyle or due to certain behavioral factors. Conservatively treated patients stabilized in weight after 2 years $(-0.9 \mathrm{~kg} \pm 5.8, n=27)$, while surgically treated patients did lose weight $(-12.1 \mathrm{~kg} \pm 16.9, n=7)$. One patient suffered from an ulcerative stenosis at the gastroenterostomy after limb length alteration.

Conclusions: a conservative treatment was the most frequently advocated treatment by the MDT. A surgical treatment resulted in successful weight loss, although only a few patients were selected for this by the MDT. A multidisciplinary approach can be beneficial for the identification of lifestyle and behavioral factors.

Keywords: bariatric surgery, obesity, weight regain, multidisciplinary team, revisional surgery

\section{Introduction}

B ARIATRIC SURGERY HAS proven to be the most effective treatment for obesity to achieve long-term substantial weight loss. ${ }^{1,2}$ However, $\sim 25 \%$ of patients do not respond well as they lose an insufficient amount of weight, or regain weight after sufficient weight loss. ${ }^{3,4}$ These phenomena can be described as primary nonresponse and secondary nonresponse. One can distinguish between these two types of nonresponse by applying a cutoff score. Frequently used cutoff scores are the amount of excess weight loss (EWL) and the amount of total weight loss (TWL) reported 1 to 2 years postsurgery. ${ }^{5-7}$ The etiology for nonresponse can be lifestyle related, but can also be explained by anatomical alterations like a dilated pouch, dilated sleeve, dilated gastroenterostomy, or fistula formation such as gastrogastric fistula. ${ }^{8,9}$
Revisional bariatric surgery constitutes a popular solution for patients with nonresponse. ${ }^{10}$ Commonly offered procedures are conversion from sleeve gastrectomy (SG) to Roux-en-Y gastric bypass (RYGB), one anastomosis gastric bypass/mini gastric bypass (OAGB/MGB), lengthening of biliopancreatic limb, band, or ring placement, revision of the gastric pouch and/or stoma, and a biliopancreatic diversion/duodenal switch (BPD/DS). ${ }^{7-13}$ To date, the long-term efficacy and safety of these procedures is difficult to predict. Lengthening of the biliopancreatic limb may result in severe malnutrition leading to the need for reoperation, whereas ring placement may result in reoperation due to dysphagia and/or ring migration. ${ }^{8,13}$

In 1991, the National Institutes of Health Consensus Statement advocated that a multidisciplinary team (MDT) is required to optimize bariatric patient care. ${ }^{14}$ This resulted in the formation of dedicated teams consisting of bariatric surgeons,

\footnotetext{
${ }^{1}$ Department of Surgery, Máxima Medical Center, Veldhoven, The Netherlands.

${ }^{2}$ Research School NUTRIM, Department of Surgery, Maastricht University Medical Center, Maastricht, The Netherlands.

*ORCID ID (https://orcid.org/0000-0001-6582-5255).

Preprint server: a preprinted version has been published on Research Square on September 2, 2020. https://www.researchsquare.com/ article/rs-48047/v2. The DOI number is $10.21203 / \mathrm{rs} .3 . r s-48047 / \mathrm{v} 2$.
} 
obesity physicians, dieticians, physical therapists, and medical psychologists. The beneficial effect of MDTs on surgical outcomes has extensively been described in the field of surgical oncology ${ }^{15-17}$; however, the effect of a MDT on nonresponse after bariatric surgery is relatively poorly understood. It was Srivastava and Buffington who demonstrated that an intensive multidisciplinary lifestyle intervention combined with medication could improve early weight loss in patients with nonresponse. ${ }^{18}$ This suggests that the role of a MDT needs further expansion in the management of nonresponders after bariatric surgery and triggers the need for a more extensive analysis. The aim of this study was to describe the added value of a multidisciplinary approach, in a bariatric tertiary referral center, on treatment strategy in nonresponders after bariatric surgery.

\section{Materials and Methods}

\section{Study population}

Data about nonresponders after RYGB and SG was collected in our center from the first of January 2016 till the first of December 2020. Patients were included if they regained $\geq 5 \%$ weight with respect to the lowest postoperative weight after RYGB or SG (i.e., nadir weight). At the moment of inclusion, $\geq 5 \%$ regain was a commonly used cutoff score. ${ }^{6}$ Patients were excluded in case of a banded RYGB and OAGB/MGB because these were less frequently performed procedures and this would have introduced heterogeneity otherwise. A history of laparoscopic adjustable gastric banding or Mason gastroplasty before the RYGB or SG was no criteria for exclusion. Ethical approval was obtained from the Medical Ethics Committee of our center, reference number: N19.054 (L19.065). For this type of study, formal consent from all individual participants was not required.

The primary procedure could have taken place in our center or elsewhere. In our center, all patients were screened for primary bariatric surgery by a MDT, and IFSO criteria were used for qualification. ${ }^{19}$ Patients were monitored in the outpatient clinic by members of the MDT for a period of 5 years. Patients were categorized as primary nonresponders if the EWL was $<50 \%$ after primary surgery; patients were categorized as secondary nonresponders if the EWL exceeded the $50 \%$ EWL threshold and a regain of $>5 \%$ was reported as per nadir weight. The below section elaborates on the process and approach taken before and during the multidisciplinary assessment.

\section{Assessment before MDT meeting}

Initial assessment of the patient was done by a bariatric surgeon. Subsequently, the patient was referred to a dietician and physical therapist for assessment of nutritional habits and physical activity. The dietician focused on food intake, food choices, feelings of satiety, and hunger and signs of emotional eating. The physical therapist focused on activity habits. If indicated, consultation by a medical psychologist was offered.

\section{MDT meeting}

Following individual consultation by all team members, the treatment strategy was discussed in a joint multidisciplinary meeting with weekly occurrence. At least one member of the following fields of expertise attended this meeting: bariatric surgeon (chair), nurse practitioner, dietician, physical therapist, and medical psychologist. Notably, under certain circumstances, the patient was discussed in the meeting despite that this patient was not seen by all team members (e.g., persistent lack of attendance at one of the appointments).

\section{Treatment strategy}

After evaluation by the MDT, a decision was taken whether the patient needed a lifestyle and/or behavioral intervention or whether the patient was qualified for revisional surgery. For the purpose of this study, treatment options were divided into conservative and surgical treatment (Fig. 1). A conservative treatment consisted of a nutritional and/or physical intervention, summarized as "lifestyle." A nutritional intervention was indicated, for example, in case of unhealthy food choices and detrimental eating patterns, whereas a physical intervention was indicated in case of a sedentary lifestyle with the goal to increase activity habits. Moreover, a behavioral intervention was indicated if there were signs of emotional eating and problems in impulse control. If there were signs indicating an eating disorder, patients were referred to a psychiatric clinic specialized in treatment of such disorders.

The indication for revisional surgery was not based on the degree of weight loss or regain, so no cutoff scores were applied by any surgeon. The type of procedure depended on the index procedure, perioperative findings, and expert opinion. Preoperative upper gastrointestinal series and upper endoscopy were performed in patients who were offered revisional surgery.

\section{Study outcomes}

The primary outcome was the initiated treatment by the MDT, either conservatively or surgically. Secondary outcomes were weight loss achieved in a period of 4 years after start of the treatment and complications after surgical treatment. Weight loss was described as \%EWL, which can be calculated as follows: (preoperative weight - nadir weight)/ (preoperative weight - ideal body weight) $\times 100 \%$. Ideal body weight was based on a body mass index (BMI) of $25 \mathrm{~kg} / \mathrm{m}^{2}$; initial body weight was the weight at the moment of screening. Weight loss was also expressed in \%TWL, which can be calculated as follows: (preoperative weight nadir weight)/preoperative weight $) \times 100 \%$, or (postoperative highest weight - postoperative lowest weight achieved after treatment of nonresponse)/postoperative highest weight $\times$ $100 \%$. The percentage of regain was calculated as percentage $\mathrm{kg}$ gained after reaching the lowest postoperative weight (nadir).

\section{Statistical analyses}

Quantitative data are presented as mean with standard deviation (range) or median with interquartile range; categorical data are expressed in numbers and percentages. A paired $t$-test was performed to compare the weight before and after the treatment of nonresponse initiated by the MDT. All analyses were performed using the program Statistical Package for Social Sciences version number 22.0 (IBM SPSS 22.0; Chicago, IL). 


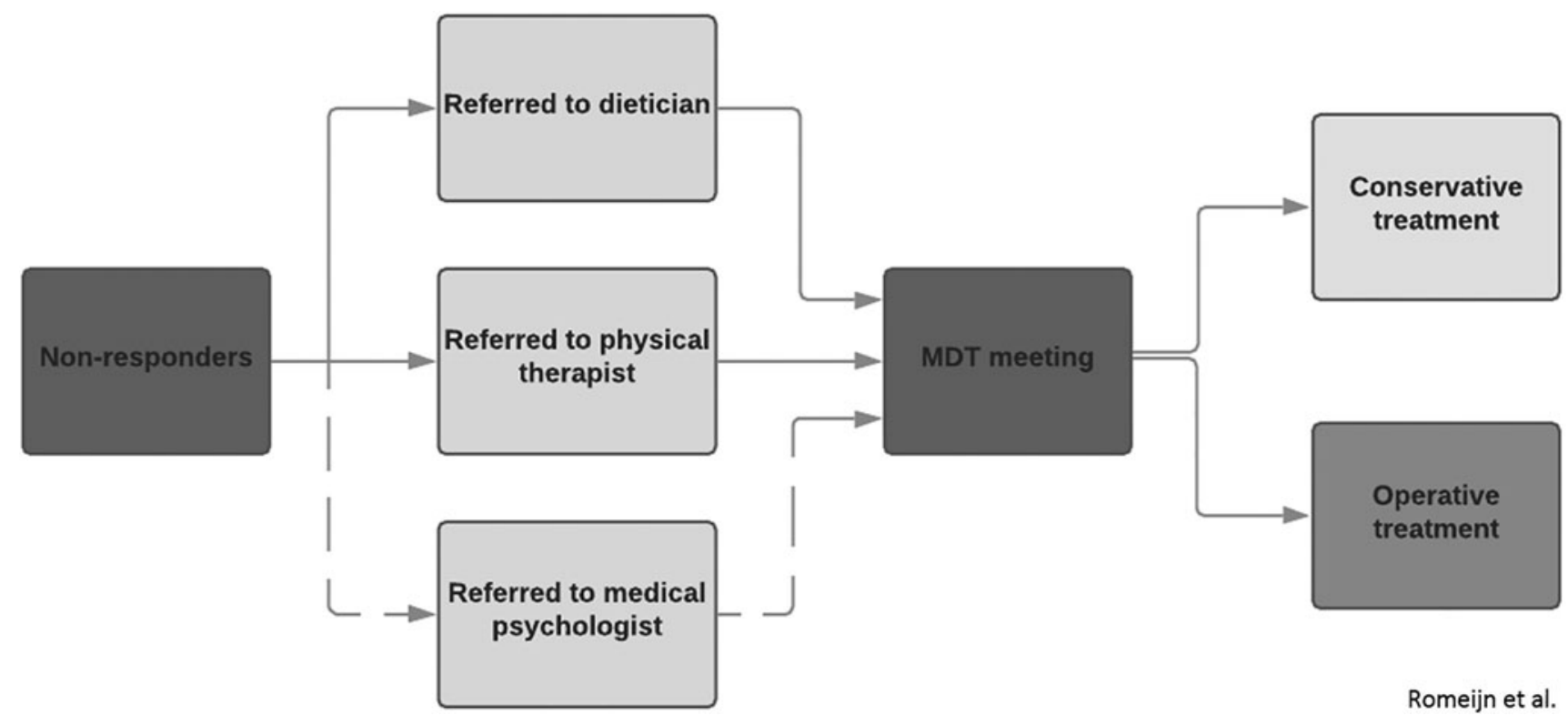

FIG. 1. Flowchart of multidisciplinary management in patients with nonresponse after bariatric surgery. MDT, multidisciplinary team.

\section{Results}

\section{Description of the population}

A total of 119 patients were initially included in the study. Fifteen patients were excluded due to either having a banded RYGB $(n=9)$, an OAGB/MGB $(n=2)$, or because they did not receive $\mathrm{RYGB}$ or $\mathrm{SG}$ but a different procedure (i.e., laparoscopic adjustable gastric banding $n=3$, BPD $n=1$ ). Of the 104 remaining patients, 21 patients did not attend their appointment with the dietician, physical therapist, and/or medical psychologist. Therefore, no optimal treatment could be advised and, consequently, these patients were excluded from further analysis. All 83 remaining patients were referred, before the multidisciplinary meeting, to a dietician and a physical therapist. Twenty-six patients (31.3\%) were referred to a medical psychologist as well.

The baseline characteristics of the 83 included patients are demonstrated in Table 1 . The group of conservatively treated patients consisted of 73 patients $(88 \%)$, whereas the group of surgically treated patients consisted of 10 patients $(12 \%)$. There were no significant differences in terms of gender, preoperative $\mathrm{BMI}$, and percentage of regain between the two groups. Based on the aforementioned definitions, 14 patients $(16.9 \%)$ were defined as primary nonresponders, who received a conservative treatment. The remaining 69 patients $(83.1 \%)$ were defined as secondary nonresponders and within this group, 59 patients received a conservative treatment, and 10 patients a surgical treatment.

When focusing on the conservative treatment, 63 patients $(86 \%)$ received a nutritional intervention, 46 patients $(63 \%)$ a physical intervention, and 18 patients $(25 \%)$ a behavioral intervention. When focusing on the surgical treatment, four different procedures were performed as described in Table 2. The index procedure was RYGB in eight patients and SG in two patients. In particular, two patients with prior SG underwent conversion to RYGB; three patients with perioperative common limb lengths between 440 and $600 \mathrm{~cm}$ underwent shortening of the common limb to $200-380 \mathrm{~cm}$; four patients with a perioperative large pouch and/or stoma underwent resizing; and one patient received a gastric ring (Minimizer).

\section{Weight loss outcomes}

Table 3 displays the effect of the treatment, initiated by the MDT up to 4 years after start of the treatment. As result of a conservative treatment, patients lost on average $0.9 \mathrm{~kg}$ within 2 years $(\mathrm{SD}=5.8)$ and gained $0.2 \mathrm{~kg}$ within 4 years $(\mathrm{SD}=9.4)$. Recalculated in \% TWL, the weight loss was $1.2 \%(\mathrm{SD}=5.5)$, $0.7 \%(\mathrm{SD}=6.3), 2.7 \%(\mathrm{SD}=10.5)$, and $0 \%(\mathrm{SD}=9.3)$ within, respectively 1, 2, 3, and 4 years. Additional analysis showed that 4 years after start of the conservative treatment $(n=17)$ $47 \%$ lost weight, while $53 \%$ gained weight. As result of a surgical treatment, patients lost on average $12.1 \mathrm{~kg}$ within 2 years $(\mathrm{SD}=16.9)$ and even more within 3 and 4 years; however, only a small number of patients was assessed at these time points. The weight loss 1,2 , and 3 years after revisional surgery was statistically significant $(p \leq 0.01)$. Recalculated in \% TWL, the weight loss was $12.1 \%(\mathrm{SD}=12.0), 11.6 \%$ $(\mathrm{SD}=15.8), 26.9 \%(\mathrm{SD}=0.6)$, and $23.9 \%(n=1)$ within, respectively, 1, 2, 3, and 4 years.

\section{Complications after surgical treatment}

One postoperative complication occurred in a patient with a history of gastric banding, followed by RYGB and subsequent alteration of the limb length. This patient developed an ulcerative stenosis at the gastroenterostomy 1 year after alteration, presumably due to nonsteroidal anti-inflammatory drugs use and the presence of Helicobacter pylori. The patient was successfully treated with endoscopic dilatation and received eradication therapy for this H. pylori.

\section{Lost to follow-up}

After 2 years, 49 patients $(59.1 \%)$ were lost to follow-up, and after 4 years, this number increased to 65 patients 
Table 1. Baseline Characteristics of the Study Population

\begin{tabular}{|c|c|c|c|}
\hline & Total, $\mathrm{n}=83$ & $\begin{array}{c}\text { Conservative } \\
\text { treatment, } \mathrm{n}=73\end{array}$ & $\begin{array}{c}\text { Surgical } \\
\text { treatment, } \mathrm{n}=10\end{array}$ \\
\hline \multicolumn{4}{|l|}{ Gender, $n(\%)$} \\
\hline Female & $75(90.4)$ & $66(90.4)$ & $9(90.0)$ \\
\hline $\begin{array}{l}\text { Age at the time of MDT } \\
\text { meeting (years) }\end{array}$ & $43.7 \pm 9.8(41.6-45.8)$ & $44.0 \pm 9.9(41.7-46.3)$ & $41.4 \pm 9.2(34.9-47.9)$ \\
\hline \multicolumn{4}{|l|}{ Preoperative comorbidities, $n(\%)$} \\
\hline Hypertension & $17(20.5)$ & $14(19.2)$ & $3(30.0)$ \\
\hline Type II diabetes & $7(8.4)$ & $5(6.8)$ & $2(20.0)$ \\
\hline Dyslipidemia & $4(4.8)$ & $4(5.5)$ & - \\
\hline OSAS & $7(8.4)$ & $7(9.6)$ & - \\
\hline Osteoarthritis & $5(6.0)$ & $5(6.8)$ & - \\
\hline \multicolumn{4}{|l|}{ History of bariatric surgery, $n(\%)$} \\
\hline LAGB & $17(17.5)$ & $14(19.2)$ & $3(30.3)$ \\
\hline Mason & $6(7.2)$ & $6(8.5)$ & - \\
\hline SG & $5(6.0)$ & $5(6.8)$ & - \\
\hline \multicolumn{4}{|l|}{ Index procedure, $n(\%)$} \\
\hline RYGB & $73(88.0)$ & $65(89.0)$ & $8(80.0)$ \\
\hline $\mathrm{SG}$ & $10(12.0)$ & $8(11.0)$ & $2(20.0)$ \\
\hline Laparoscopy & $79(95.2)$ & $69(94.5)$ & $10(100.0)$ \\
\hline \multicolumn{4}{|l|}{ Complications, $n(\%)$} \\
\hline No complications & $73(88.0)$ & $63(86.3)$ & $10(100.0)$ \\
\hline Clavien-Dindo grade I & $1(1.2)$ & $1(1.4)$ & - \\
\hline Clavien-Dindo grade II & $2(2.4)$ & $2(2.7)$ & - \\
\hline Clavien-Dindo grade III & $7(8.4)$ & $7(9.6)$ & - \\
\hline Preoperative weight $(\mathrm{kg})$ & $127.6 \pm 20.7(123.0-132.1)$ & $126.2 \pm 20.3(123.0-132.1)$ & $137.5 \pm 21.6(122.1-152.9)$ \\
\hline Preoperative BMI $\left(\mathrm{kg} / \mathrm{m}^{2}\right)$ & $44.7 \pm 7.0(43.2-46.2)$ & $44.7 \pm 7.4(43.1-46.2)$ & $44.9 \pm 3.5(42.4-47.5)$ \\
\hline Maximal EWL (\%) & $77.9 \pm 23.7(72.8-83.2)$ & $78.6 \pm 25.0(72.8-83.2)$ & $73.7 \pm 10.1(66.4-80.9)$ \\
\hline Maximal TWL (\%) & $32.9 \pm 9.7(30.8-35.0)$ & $32.9 \pm 10.2(30.8-35.0)$ & $32.2 \pm 3.6(29.7-34.8)$ \\
\hline $\begin{array}{l}\text { Amount of primary } \\
\text { nonresponse }(\%)\end{array}$ & $14(16.9)$ & $14(19.2)$ & - \\
\hline $\begin{array}{c}\text { Amount of secondary } \\
\text { nonresponse }(\%)\end{array}$ & $69(83.1)$ & $59(80.8)$ & $10(100.0)$ \\
\hline Weight regain $(\%)$ & $24.9 \pm 15.1(21.6-28.2)$ & $25.5 \pm 15.7(21.6-28.2)$ & $20.9 \pm 9.1(14.4-27.5)$ \\
\hline Interval to presentation (years) & $4.1 \pm 2.2(3.6-4.6)$ & $4.0 \pm 2.2(3.6-4.6)$ & $5.0 \pm 1.8(3.7-6.3)$ \\
\hline \multicolumn{4}{|l|}{ Analysis of nonresponse } \\
\hline Upper gastrointestinal series (\%) & $28(33.7)$ & $18(24.7)$ & $10(100.0)$ \\
\hline Endoscopy $(\%)$ & $5(6.0)$ & $3(4.1)$ & $2(20.0)$ \\
\hline
\end{tabular}

Data presented as $n(\%)$, mean with standard deviation and 95\% confidence interval. Primary nonresponse is defined as $<50 \%$ EWL. Secondary nonresponse is defined as $\geq 50 \%$ and a regain of $\geq 5 \%$ with respect to nadir weight.

BMI, body mass index; EWL, excess weight loss; LAGB, laparoscopic adjustable gastric banding; MDT, multidisciplinary team; OSAS, obstructive sleep apnoea syndrome; RYGB, Roux-en-Y gastric bypass; SG, sleeve gastrectomy; TWL, total weight loss.

Table 2. Overview of Given Treatment FOR NONRESPONSE, INITIATED BY THE Multidisciplinary TEAM

Total, $n=83$

Conservative treatment $n=73, n(\%)$

Nutritional intervention

Physical intervention

Behavioral intervention

Referred to psychiatric institution

Surgical treatment $n=10, n(\%)$

Alternation of the limb length

Revision of the gastric pouch and/or stoma

RYGB

Ring placement

$63(86.3)$

$46(63.0)$

$18(24.7)$

$4(5.5)$

$3(30.0)$

$4(40.0)$

$2(20.0)$

$1(10.0)$

Data presented as $n(\%)$.
(78.3\%). The reason of lost to follow-up is unknown. The baseline characteristics were analyzed comparing missing patients with nonmissing patients 2 years after the start of the treatment. This analysis showed that the percentage of regain was significantly higher in the group of missing patients ( $28.3 \%$ vs. $20.3 \%, p=0.02$ ). On the contrary, the prevalence of preoperative hypertension and type 2 diabetes was lower in the group of missing patients ( $10.4 \%$ vs. $34.3 \%, p=0.01$ and $2.1 \%$ vs. $17.1 \%, p=0.02$, respectively). Other baseline characteristics did not differ between the two groups.

\section{Discussion}

There is no standardized approach in the treatment of nonresponders following bariatric surgery. While ongoing studies about the efficiency of revisional surgery are being reported in literature, ${ }^{8,9,11-13}$ studies about the effect of a 


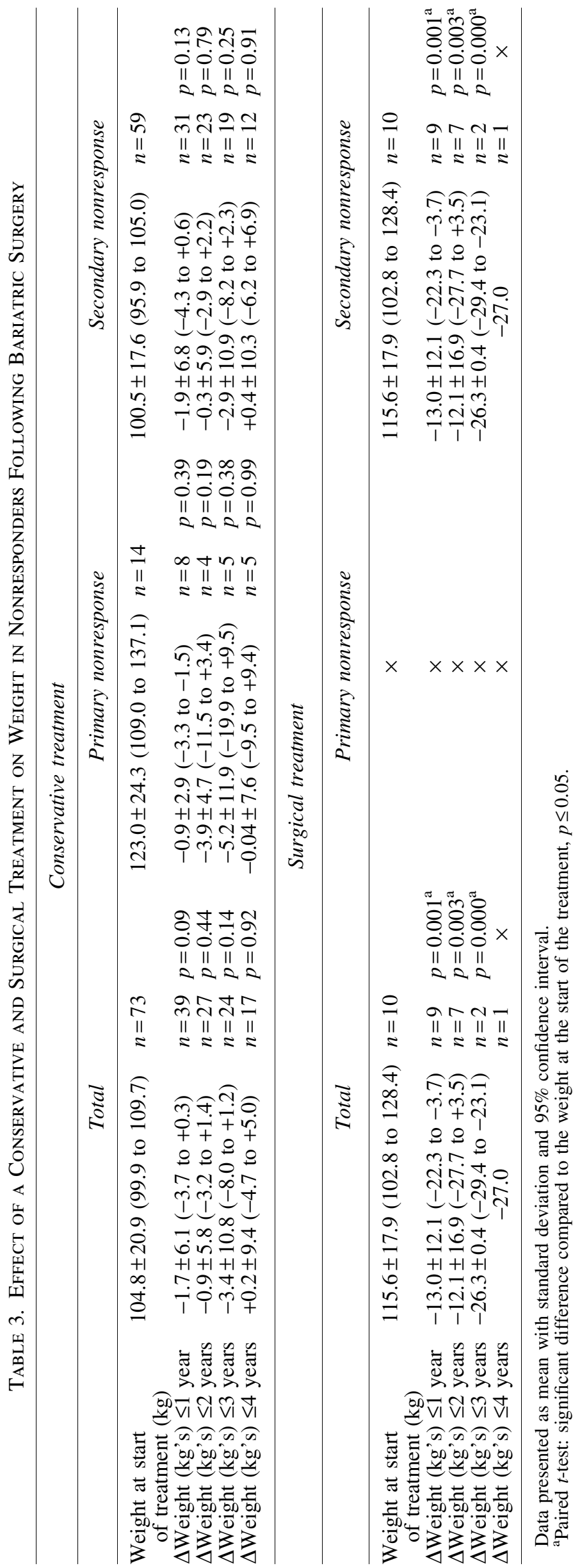


multidisciplinary approach fall behind. Although it is proposed that a multidisciplinary approach is useful in the analysis of patients with nonresponse, ${ }^{7,9,13,20}$ this study is the first in describing the added value of such a multidisciplinary approach.

The main finding of this study was that the MDT advocated a conservative treatment more frequently than a surgical treatment ( $88 \%$ vs. $12 \%)$. The majority of patients were considered not to be eligible for revisional surgery as they either had not been able to change their lifestyle or due to certain behavioral factors. Based on previous research in our center between 2012 and 2015, it has been identified that before the introduction of a MDT, $68 \%$ of the nonresponders underwent surgery after failed RYGB. ${ }^{11}$ That study included 65 patients with weight loss failure and weight regain who were consulted by a bariatric surgeon. Consultation by a dietician and physical therapist and/or medical psychologist was not scheduled on a routine basis. Furthermore, no joint meeting by the MDT took place. The result of this study $(68 \%$ revisional surgery) is in sharp contrast with the result of the current study (12\% revisional surgery). One can argue that the MDT may have underselected appropriate candidates for revisional surgery or alternatively may have optimized the selection of candidates. The small sample size and heterogeneity in revisional procedures in the current study restricts making firm statements about this.

When reviewing weight loss outcomes, the weight loss achieved by revisional surgery was superior to the weight loss achieved by a conservative treatment. Notably, one could also argue that the weight was sustained as result of a conservative treatment, indicating that it may prevent patients from gaining more weight in the future. The question arises why a conservative treatment should be advocated as this resulted in less weight loss. In the context of revisional surgery it is worth noting that a patient is exposed to the risks of major complications and the risk of unsustainable weight loss in the long term. ${ }^{8,21}$ A reason for this can be that surgery does not resolve the lifestyle and/or behavioral problems that may have contributed to nonresponse in the first place..$^{20,22,23}$

The observed complication rate within our study is in line with other literature. Complication rate after pouch/ anastomosis revision is estimated at 3.5\% and after limb alteration at $12 \% .{ }^{8}$ Revision of the gastric pouch and/or stoma was most frequently performed in this study. The four patients who underwent this procedure did not suffer from any complications. From the three patients who underwent limb alternation, one patient suffered from an ulcerative stenosis at the gastroenterostomy, which is a frequently reported complication in literature. $^{24,25}$

This study distinguished outcomes between primary and secondary nonresponders. Previous studies did not report treatment outcomes using this classification, although it is proposed as standardized terminology. ${ }^{6,10}$ This study supports this classification as it was found that patients with secondary nonresponse rather than primary nonresponse were treated surgically. This may indicate the need for a different treatment strategy in patients with primary and secondary nonresponse. A note of caution might be appropriate as there were demographical differences between the two groups. Speculatively, primary nonresponse might be a manifestation of insufficiently treated or even untreated eating behaviors and/or psychological problems, whereas

\author{
Table 4. Checklist of Factors That Can Be Used \\ During THE ASSESSMENT OF A PATIENT \\ With NONRESPONSE AdVOCATING \\ a Conservative or Surgical Treatment
}

\begin{tabular}{|c|c|}
\hline $\begin{array}{l}\text { Factors in favor of } \\
\text { conservative treatment }\end{array}$ & $\begin{array}{c}\text { Factors in favor } \\
\text { of surgical treatment }\end{array}$ \\
\hline $\begin{array}{l}\text { Excessive dietary intake } \\
\text { Inappropriate food choices } \\
\text { Lack of satiety } \\
\text { Constant hunger sensation } \\
\text { Emotional eating } \\
\text { Binge eating } \\
\text { Sweet eating } \\
\text { Grazing behavior } \\
\text { Physically inactive } \\
\text { Mental health disorder, } \\
\text { e.g., depression, anxiety, } \\
\text { personality disorders }\end{array}$ & $\begin{array}{l}\text { Signs of surgical failure, } \\
\text { e.g., pouch or stoma } \\
\text { dilatation, } \\
\text { gastrogastric fistula } \\
\text { Dietary compliance } \\
\text { No signs of maladaptive } \\
\text { eating habits } \\
\text { Physically active } \\
\text { No signs of mental health } \\
\text { disorder } \\
\text { No signs of alcohol or drug } \\
\text { use }\end{array}$ \\
\hline
\end{tabular}

secondary nonresponse might indicate anatomical problems. This theory warrants further research to obtain more information about the etiology and treatment strategy that is most efficient per nonresponse type.

This retrospective study has several limitations that should be considered. Not all patients received their primary surgery in our center and therefore information about preoperative screening and treatment could have been missed. It is questionable whether certain lifestyle and/or behavioral factors were present before primary surgery and whether the patients' adjustments met the standards used in our center. Another limitation could be that the MDT experienced a learning curve as the multidisciplinary evaluation of nonresponders was introduced in 2016 in our center. It is possible that the different team members experienced a change in their evaluation and subsequent treatment. Moreover, pharmacological therapy was not used, while this has shown beneficial results in the treatment of nonresponse. ${ }^{26}$ It should also be mentioned that results regarding weight loss and complication rates are limited due to the small selected group of patients who underwent revisional surgery. Furthermore, the $20 \%$ of patients who were excluded from the analysis due to no-show may have introduced selection bias, as well as the patients who did not attend their follow-up appointments after the treatment was set. The latter may be explained by further weight regain or by a loss of confidence in the MDT. ${ }^{27}$ Notwithstanding these limitations, the study offers insights into the treatment of nonresponders after bariatric surgery. For further practices, a checklist of relevant factors was made proposing a conservative or surgical treatment in nonresponders (Table 4).

\section{Conclusion}

This study demonstrated that when patients with nonresponse after bariatric surgery are evaluated by a MDT, a conservative treatment is more often applied than a surgical treatment. The MDT identified patient-specific factors presumably contributing to the nonresponse and these factors constituted the framework for a conservative treatment. At present, the question that remains unanswered is whether a 
multidisciplinary approach set the right treatment as perhaps the selection of candidates for revisional surgery was incorrect. More studies are required to position the multidisciplinary approach in the treatment of nonresponse, as well as determine what kind of revisional procedure should be preferred.

\section{Authors' Contributions}

M.R., L.J., F.D., and W.L., conceived the original study and design. M.R. is responsible for data collection, data recording, and preparing the article. M.U. and A.L., contributed to writing the article. All authors have read and approved the final article.

\section{Author Disclosure Statement}

No competing financial interests exist.

\section{Funding Information}

No funding has been received.

\section{References}

1. Chang SH, Stoll CR, Song J, Varela JE, Eagon CJ, Colditz GA. The effectiveness and risks of bariatric surgery: an updated systematic review and meta-analysis, 2003-2012. JAMA Surg 2014;149:275-287.

2. O'Brien PE, McPhail T, Chaston TB, Dixon JB. Systematic review of medium-term weight loss after bariatric operations. Obes Surg 2006;16:1032-1040.

3. Hsu LK, Benotti PN, Dwyer J, Roberts SB, Saltzman E, Shikora $\mathrm{S}$ et al. Nonsurgical factors that influence the outcome of bariatric surgery: a review. Psychosom Med 1998;60:338-346.

4. Magro DO, Geloneze B, Delfini R, Pareja BC, Callejas F, Pareja JC. Long-term weight regain after gastric bypass: a 5-year prospective study. Obes Surg 2008;18: 648-651.

5. van de Laar AW, Nienhuijs SW, Apers JA, van Rijswijk AS, de Zoete JP, Gadiot RP. The Dutch bariatric weight loss chart: a multicenter tool to assess weight outcome up to 7 years after sleeve gastrectomy and laparoscopic Roux-en-Y gastric bypass. Surg Obes Relat Dis 2019; 15:200-210.

6. Bonouvrie DS, Uittenbogaart M, Luijten AAPM, van Dielen FMH, Leclercq WKG. Lack of standard definitions of primary and secondary (Non)responders after primary gastric bypass and gastric sleeve: a systematic review. Obes Surg 2019;29:691-697.

7. Cambi MPC, Baretta GAP, Margo DDO, Boguszewski CL, Ribeiro IB, Jirapinyo $\mathrm{P}$, et al. Multidisciplinary approach for weight regain-how to manage this challenging condition: an expert review. Obes Surg 2021. [Epub ahead of print]; DOI:10.1007/s11695-020-05164-1.

8. Tran DD, Nwokeabia ID, Purnell S, Zafar SN, Ortega G, Hughes $\mathrm{K}$, et al. Revision of Roux-En-Y gastric bypass for weight regain: a systematic review of techniques and outcomes. Obes Surg 2016;26:1627-1634.

9. Maleckas A, Gudaityté R, Petereit R, Venclauskas L, Veličkiené $\mathrm{D}$. Weight regain after gastric bypass: etiology and treatment options. Gland Surg 2016;5:617-624.

10. Uittenbogaart M, de Witte E, Romeijn MM, Luijten AAPM, van Dielen FMH, Leclercq WKG. Primary and secondary nonresponse following bariatric surgery: a survey study in current bariatric practice in the Netherlands and Belgium. Obes Surg 2020;30:3394-3401.

11. Uittenbogaart M, Leclercq WK, Luijten AA, van Dielen FM. Laparoscopic adjustable gastric banding after failed Roux-En-Y gastric bypass. Obes Surg 2017;27: 381-386.

12. Musella M, Bruni V, Greco F, Raffaelli M, Lucchese M, Susa A, et al. Conversion from laparoscopic adjustable gastric banding (LAGB) and laparoscopic sleeve gastrectomy (LSG) to mini/one anastomosis gastric bypass (MGB/OAGB): preliminary data from a multicenter retrospective study. Surg Obes Relat Dis 2019;15;1332-1339.

13. Karmali S, Brar B, Shi X, Sharma AM, de Gara C, Birch DW. Weight recidivism post-bariatric surgery: a systematic review. Obes Surg 2013;23:1922-1933.

14. Gastrointestinal surgery for severe obesity: national Institutes of Health Consensus Development Conference Statement. Am J Clin Nutr 1992;55(2 Suppl):615S-619S.

15. Pillay B, Wootten AC, Crowe H, Corcoran N, Tran B, Bowden $\mathrm{P}$, et al. The impact of MDT meetings on patient assessment, management and outcomes in oncology settings: a systematic review of the literature. Cancer Treat Rev 2016;42:56-72.

16. Wright FC, De Vito C, Langer B, Hunter A; Expert Panel on Multidisciplinary Cancer Conference Standards. Multidisciplinary cancer conferences: a systematic review and development of practice standards. Eur J Cancer 2007;43: 1002-1010.

17. Taylor C, Munro AJ, Glynne-Jones R, Griffith C, Trevatt P, Richards M, et al. MDT working in cancer: what is the evidence? BMJ 2010;340:c951.

18. Srivastava G, Buffington C. A Specialized Medical Management Program to address post-operative weight regain in bariatric patients. Obes Surg 2018;28:2241-2246.

19. Fried M, Yumuk V, Oppert JM, Scopinaro N, Torres A, Weiner R, et al. International Federation for Surgery of obesity and metabolic disorders-European chapter (IFSOEC); European Association for the Study of obesity (EASO); European Association for the Study of obesity obesity management task force (EASO OMTF). Interdisciplinary European guidelines on metabolic and bariatric surgery. Obes Surg 2014;24:42-55.

20. Stoklossa CJ and Atwal S. Nutrition care for patients with weight regain after bariatric surgery. Gastroenterol Res Pract 2013;2013:256145.

21. Hamdi A, Julien C, Brown P, Woods I, Hamdi A, Ortega G, et al. Midterm outcomes of revisional surgery for gastric pouch and gastrojejunal anastomotic enlargement in patients with weight regain after gastric bypass for morbid obesity. Obes Surg 2014;24:1386-1390.

22. Livhits M, Mercado C, Yermilov I, Parikh JA, Dutson E, Mehran A, et al. Preoperative predictors of weight loss following bariatric surgery: systematic review. Obes Surg 2012;22:70-89.

23. Masood A, Alsheddi L, Alfayadh L, Bukhari B, Elawad R, Alfadda AA. Dietary and lifestyle factors serve as predictors of successful weight loss maintenance postbariatric surgery. J Obes 2019;2019:7295978.

24. Palermo M, Acquafresca PA, Rogula T, Duza GE, Serra E. Late surgical complications after gastric bypass: a literature review. Arq Bras Cir Dig 2015;28:139-143.

25. Pratt JSA. Roux-en-Y Gastric Bypass: Stomal Stenosis. In: Nguyen NT, De Maria EJ, Ikramuddin S, Hutter MM (eds). 
The SAGES Manual. New York, NY: Springer, 2008. DOI: 10.1007/978-0-387-69171-8_25.

26. Stanford FC, Alfaris N, Gomez G, Ricks ET, Shukla AP, Corey KE, et al. The utility of weight loss medications after bariatric surgery for weight regain or inadequate weight loss: a multi-center study. Surg Obes Relat Dis 2017;13: 491-500.

27. Luca P, Nicolas C, Marina V, Sarah B, Andrea L. Where are my patients? Lost and found in bariatric surgery. Obes Surg 2021. [Epub ahead of print]; DOI: 10.1007/s11695020-05186-9.
Address correspondence to: Marleen M. Romeijn, MD

Research School NUTRIM Department of Surgery Maastricht University Medical Center Universiteitssingel 40 Maastricht 6229 ER The Netherlands

E-mail:m.romeijn@maastrichtuniversity.nl; bariatric.resurge@mmc.nl 